\title{
Verhalen van plattelandspolitie - constructie van een beroepsidentiteit onder druk
}

\author{
Jan Terpstra
}

\begin{abstract}
Dit artikel richt zich op de culturele aspecten van politie in landelijke gebieden. Dit gebeurt door de verhalen van politiemensen op het platteland te analyseren. Het laat zien dat in deze verhalen enkele elementen telkens terugkeren. Kernelement daarbij is het geconstrueerde contrast met een verbeelde stedelijke politie: de plattelandspolitie zou beter ingebed zijn in de lokale gemeenschap, meer persoonlijke en directe relaties hebben met burgers, en andere strategieën gebruiken om problemen op te lossen. Politiemensen op het platteland hebben vaak het gevoel als tweederangspolitie te worden gezien en behandeld. Daar stellen zij in hun verhalen een beeld tegenover van een politie die juist competenter is en betere methoden hanteert dan de stedelijke politie, met minder geweld en escalatie. Met deze verhalen construeren de politiemensen een identiteit van de plattelandspolitie. Het is geen toeval dat deze verhalen juist nadrukkelijker naar voren komen op momenten dat de plattelandspolitie onder druk staat.
\end{abstract}

In onze huidige, sterk verstedelijkte maatschappij bestaat de neiging het specifieke van de plattelandssamenleving over het hoofd te zien en als achterhaald verschijnsel te beschouwen. Vanuit dit dominante stedelijke perspectief is het platteland niet meer dan een dunbevolkt stedelijk aanhangsel, waar men hoogstens een onverstaanbaar dialect in stand probeert te houden of om toeristische redenen de rurale idylle probeert te koesteren (Yarwood 2005a en 2005b). Een vergelijkbaar perspectief overheerst als het gaat om de politie op het platteland. Het specifieke van politie en politiewerk in een rurale context lijkt in de regel te worden genegeerd. Voor zover er aandacht aan wordt besteed, wordt het beeld nogal eens bepaald door romantische noties gebaseerd op een (deels vermoedelijk fictief) verleden (Mawby 2004, 431; Yarwood 2001). Opmerkelijk genoeg is ook vanuit de politiewetenschap de belangstelling voor deze thematiek gering. In Nederland ontbreekt onderzoek hiernaar nagenoeg. ${ }^{1}$ Ook in Engeland en de VS gaat in onderzoek verreweg de meeste aandacht uit naar de stedelijke politie (Christensen en Crank 2001). Toch is daar de afgelopen decennia wel een kleine stroom van onderzoekspublicaties ontstaan over 'rural policing' (Mawby en Yarwood 2011).

Is de hoeveelheid onderzoek naar politie op het platteland al gering, de aandacht voor culturele aspecten daarvan is nog beperkter. Toch moet daarin voor een belangrijk deel het antwoord worden gezocht op de vraag naar de identiteit van de politie op het platteland. Daarbij gaat het onder meer om de vraag hoe politiemensen in plattelandsgebieden zichzelf en hun werk zien en hoe zij daaraan een 
specifieke betekenis toekennen. Dit thema staat hier centraal. Daarbij richt de aandacht zich op de wijze waarop die identiteit geconstrueerd wordt in telkens terugkerende verhalen van politiemensen op het platteland over de politie daar. Deze verhalen ben ik de afgelopen jaren in verschillende onderzoeken binnen de politie tegengekomen (onder meer in Terpstra 2002; Terpstra 2008). Ook in een eerdere studie van Gunter Moor en Peeters (1996) stuitten onderzoekers op dit verschijnsel. In een recent onderzoek naar de inrichting en het functioneren van basisteams binnen de Nationale Politie (Terpstra et al. 2016) bleek opnieuw hoe belangrijk deze verhalen zijn voor het begrijpen van de lokale politie op het platteland. In twee van de drie onderzochte plattelandsteams keerden deze verhalen in allerlei varianten tijdens interviews en observaties regelmatig terug. Vanwege de centrale positie die zij innemen, wordt hier uitgebreider op deze verhalen ingegaan. Daarbij wordt empirisch gesteund op het laatstgenoemde onderzoek. ${ }^{2}$

De opbouw van dit artikel is als volgt. Eerst wordt de bestaande literatuur behandeld over politie en politiewerk op het platteland (1). Vervolgens wordt ingegaan op politieverhalen als onderdeel van politiecultuur en als bron voor onderzoek daarnaar (par. 2). Daarna worden de verhalen van politiemensen op het platteland geanalyseerd (par. 3). Tot slot komen enkele achtergronden daarvan aan bod (par. 4).

\section{Politie op het platteland: literatuur}

Zoals in het voorgaande al werd opgemerkt, is in Nederland nauwelijks onderzoek gedaan naar de politie op het platteland. In het Verenigd Koninkrijk en de Verenigde Staten bestaat meer onderzoek rond dit thema. De belangrijkste daarvan zijn kort samengevat door Mawby (2011, 12-13). Deze constateert dat de politie op het platteland meer voldoet aan het beeld van community oriented policing. Politiemensen op het platteland zijn vaker zelf afkomstig uit de lokale gemeenschap, zijn daarin beter geïntegreerd en verrichten een breder scala van (dienstverlenende) taken dan hun collega's in de stad. In vergelijking met hen zijn zij meer generalisten. Hun (vaker informele) optreden wordt door burgers positiever beoordeeld (zie ook Weisheit, Wells en Falcone 1994; Shapland en Vagg 1987; Marshall en Johnson 2005; Verwee 2009). In verschillende studies is erop gewezen dat niet alleen het lagere niveau van criminaliteit op het platteland hierbij mogelijk een rol speelt. Vooral de sterkere informele sociale controle is hierbij van belang. Dit biedt de politie de mogelijkheid daar in haar werk op voort te bouwen (Mawby 2004; Marshall en Johnson 2005; Weisheit, Wells en Facone 1994; Weisheit en Wells 1996).

Volgens het overzicht van Mawby (2011) kenmerkt het werk van politiemensen op het platteland zich daarnaast door verschillende problemen. Zo hebben zij minder mogelijkheden snel assistentie van collega's te krijgen (onder meer vanwege de grotere afstanden) en beschikken zij over minder technische hulpmidde-

2 Zie voor een uitvoerige beschrijving van de in deze studie gehanteerde methoden van onderzoek: Terpstra et al. 2016. 
len. Weliswaar staan zij op grotere afstand van hun leiding (en hebben daardoor meer autonomie), maar hier staat tegenover dat zij vanuit de lokale gemeenschap meer in de gaten worden gehouden.

Het is de vraag hoe relevant deze bevindingen zijn voor de huidige Nederlandse situatie. Het politiebestel in de VS is meer gedecentraliseerd dan het Nederlandse. Een deel van de wat oudere bevindingen uit het Verenigd Koninkrijk (zoals het gebrek aan scheiding tussen werk en privé bij de plattelandspolitie) is onvergelijkbaar met de huidige situatie in Nederland.

Over de cultuur van de plattelandspolitie is nog minder bekend. De belangstelling vanuit de politiewetenschap hiervoor is beperkt. Zo bevat het overzicht van politiecultuur van de hand van Cockcroft (2013) geen enkele verwijzing naar rural policing.

Toch zijn er vooral Engelse auteurs die menen dat de plattelandspolitie een eigen culturele identiteit heeft en daarin sterk verschilt van de stedelijke politie (bijvoorbeeld Smith en Somerville 2013). Deze opvatting is onder meer gebaseerd op enkele, deels al oudere studies van Britse antropologen. In het volgende worden drie van deze studies kort besproken. Twee daarvan (namelijk van Banton en van Cain) kunnen worden beschouwd als klassiekers in de politiewetenschap.

De oudste studie is die van Banton uit 1964. Zijn onderzoek vond plaats in zowel stedelijke als rurale gebieden, in de VS en in Schotland. Uitgangspunt in zijn studie is dat het optreden van de politie sterk afhankelijk is van de (informele) sociale controle en sociale integratie in de lokale samenleving. Omdat sociale controle en integratie op het platteland in de regel meer aanwezig zijn dan in de stad en omdat daar een sterkere morele consensus bestaat waarop de politie kan aansluiten, is de politie daar meer vredebewaarder dan (wets)handhaver. Omdat politiemensen op het platteland worden gezien als lid van de lokale gemeenschap, kiezen zij voor andere strategieën dan de stedelijke politie. Zij beseffen dat als zij 's ochtends iemand bekeuren, zij hem 's avonds weer in de pub kunnen tegenkomen. In zo'n context probeert de politie het gedrag van burgers te beïnvloeden door aan te sluiten bij de morele consensus in de gemeenschap. Bij een kloof tussen politie en gemeenschap (zoals in de stad vaak het geval is) ontbreekt een dergelijke consensus. De politie grijpt dan eerder naar handhaving en hardere middelen, aldus Banton (1964, 172-175). Bij uitholling van de sociale integratie zal volgens Banton een politiestrategie berustend op praten en waarschuwen, aan doeltreffendheid verliezen. Als gevolg daarvan zal ook de politie op het platteland op den duur overgaan op meer handhavende strategieën, aldus Banton (1964, 136-137).

Ook Cain (1973) vergelijkt in haar studie de grootstedelijke met de plattelandspolitie. Ook zij constateert dat politiemensen op het platteland beter geïntegreerd zijn in de lokale gemeenschap dan hun collega's in de stad. In de lijn van Banton laat ook Cain zien dat de politie in stabiele en homogene samenlevingen anders opereert dan in een heterogene en/of instabiele context. Als de politie (zoals in de stad vaak het geval is) op afstand staat, beschikt zij over minder gedetailleerde en 
accurate informatie. Als gevolg daarvan grijpt de politie dan volgens Cain (1973, 19) eerder naar hard optreden, om maar geen fouten te maken.

Op het platteland wordt de vraag wat relevant politiewerk is veel meer gedefinieerd aan de hand van opvattingen en verwachtingen van burgers. Dat wordt versterkt, omdat burgers en politiemensen daar vergelijkbare perspectieven en zienswijzen hanteren. Politiemensen krijgen daar veel meer informatie door hun frequente informele contacten met burgers (het zogenoemde 'praatje pot'). In een dergelijke context is sprake van 'goed' politiewerk, zowel in de ogen van politiemensen als van burgers, als die vragen worden opgepikt die burgers belangrijk vinden. Criminaliteit vormt daarvan slechts een klein onderdeel. In de ogen van stedelijke politiemensen levert dat echter vaak slechts triviaal werk op (Cain 1973, 32-35, 71).

Ook Cain constateert dat op het platteland politiemensen meer vredebewaarder zijn dan handhaver. In de stedelijke context is volgens Cain een dergelijke rol echter niet vol te houden. Daar heeft de politie haar eigen criterium voor 'goed' politiewerk ontwikkeld. Dat zou vooral bestaan uit aanhoudingen. Omdat de stedelijke politie meer gespecialiseerd is, komt de gewone politiemedewerker daar echter toch weinig in aanraking met crime fighting.

Overigens, de nauwe relaties tussen politie en lokale gemeenschap op het platteland hebben volgens Cain ook schaduwzijden. Enerzijds is de politie afhankelijker van de lokale gemeenschap. Anderzijds staat de lokale politieman er vaker alleen voor: collega's zijn immers op afstand.

De derde studie die hier relevant is, is van de Engelse antropoloog en politieman Young (1993). Hij laat zien dat de Engelse politie op het platteland, ondanks schaalvergroting en fusies tussen korpsen, haar identiteit in belangrijke mate ontleend aan een gekoesterd verleden (zoals het icoon van de village bobby). Benadrukt wordt dat de politie op het platteland een eigen werkwijze en stijl heeft die sterk verschilt van die van de stedelijke politie. Ook hier houdt de politie op het platteland zich bezig met vragen en problemen die collega's in de stad als futiliteit zouden negeren (zoals een burger die bij het bureau meldt dat hij zijn eend kwijt is).

In de verhalen die politiemensen in het door Young onderzochte plattelandskorps onderling uitwisselen, wordt de eigen identiteit als plattelandspolitie steeds beklemtoond. Men zet zich daarbij af tegen de stedelijke politie, waarvan een tamelijk negatief beeld overheerst. De weerstanden tegen verandering van buitenaf (= 'de stad') zijn groot. Nieuwe leidinggevenden die van buitenaf komen, stuiten als stedelijke binnendringers op tal van belemmeringen.

Overigens komt uit de studie van Young ook het beeld naar voren van het onderzochte plattelandskorps als een aartsconservatieve organisatie met een sterk ritualistische bureaucratie. Als gevolg daarvan zou deze organisatie hoogst inefficiënt en geldverslindend zijn. De verhoudingen in het onderzochte korps lijken niet los te zien van de traditionele paternalistische klassenverhoudingen op het Engelse platteland. 
$\mathrm{Al}$ vaker is de vraag opgeworpen of het kenmerkende van de plattelandspolitie niet aan het verdwijnen is. Deze vraag werd al door Cain in 1973 (242-246) naar voren gebracht. Zij verwachtte dat veranderingen in politieorganisatie en plattelandssamenleving ertoe zouden leiden dat politie en politiecultuur op het platteland op de stedelijke politie zouden gaan lijken. Ook de invulling van politiewerk als vredebewaking zou daarmee grotendeels verdwijnen. In het verlengde hiervan meent Mawby (2004) dat sinds de tijd dat Cain haar onderzoek deed, de plattelandspolitie sterk is veranderd. Toegenomen mobiliteit en moderne communicatiemiddelen zouden hieraan hebben bijgedragen. Al verwachtte ook hij dat daarmee stedelijke en plattelandspolitie meer op elkaar zouden zijn gaan lijken, toch bleek uit zijn onderzoek dat de plattelandspolitie nog steeds aanzienlijk meer als onderdeel van de lokale samenleving wordt ervaren. Ook Loftus (2009) vindt in haar recentere onderzoek naar politiecultuur in stad en platteland dat er naast vele overeenkomsten belangrijke verschillen zijn blijven bestaan. Zo ervaren politiemensen op het platteland minder wantrouwen en vijandigheid vanuit de bevolking. Daar ook hebben politiemensen sterker het gevoel voor de 'gemeenschap' te werken.

Het voorgaande roept de vraag op in hoeverre in Nederland politiemensen op het platteland anders tegen hun werk aankijken en daaraan een specifieke identiteit toekennen. Of hebben ook hier processen van modernisering, toegenomen mobiliteit en individualisering op het platteland de ruimte voor een dergelijke specifieke politiestijl en -cultuur weggenomen?

\section{Verhalen en politiecultuur}

In menig onderzoek is opgemerkt dat politiemensen elkaar veel en uitgebreid verhalen vertellen, onder meer in de auto en kantine (Van Maanen 1978; Trujillo en Dionisopoulos 1987; Shearing en Ericson 1991; Waddington 1999; Van Hulst 2013a, 2013b). Politieverhalen vormen zowel een belangrijk onderdeel van als bron tot politiecultuur. Door deze verhalen te analyseren, is het mogelijk veelvoorkomende valkuilen in de literatuur over politiecultuur te vermijden, zoals de neiging politiecultuur op te vatten als homogeen en statisch verschijnsel, waarin nauwelijks plaats is voor actoren die deze cultuur actief (re)produceren en daarmee veranderen (Chan 1997; Terpstra 2009).

De verhalen die politiemensen elkaar vertellen zijn onder meer een manier om kennis, interpretaties, regels en een praktische moraal te delen. Dat gebeurt vooral in de vorm van anekdotes en sappige verhalen die telkens worden herhaald. Aan de hand van deze verhalen worden handvatten geboden om situaties en personen die de politie in haar werk kan tegenkomen, te begrijpen en daarmee om te gaan. Door het aanhoren van de verhalen kunnen nieuwe collega's spelenderwijs leren hoe zij relevante situaties en personen kunnen herkennen en moeten interpreteren en hoe daarbij te handelen (Terpstra 2008, 175-185).

$\mathrm{Al}$ vormt het bestuderen van politieverhalen een belangrijke manier om zicht te krijgen op de politiecultuur, toch lopen de opvattingen uiteen over hoe deze ver- 
halen te interpreteren. Globaal kan onderscheid worden gemaakt tussen twee opvattingen. De opvatting van Shearing en Ericson (1991) past bij de hiervoor gegeven analyse van de betekenis van politieverhalen. Voor hen vormen politieverhalen een centraal onderdeel van de politiepraktijk en een belangrijke manier om collega's het vak te leren. Waddington (1999) daarentegen gaat ervan uit dat er een groot verschil kan zijn tussen de verhalen van politiemensen en wat zij feitelijk doen. Dit sluit aan bij de analyse van Trujillo en Dionisopoulos (1987). Volgens Waddington zijn de verhalen die politiemensen elkaar vertellen vooral een reactie op de frustraties die hun werk met zich meebrengt. Juist omdat dat werk vaak saai is, vertellen zij elkaar verhalen waarin spanning en actie worden benadrukt. Van Hulst (2013a en b) laat in zijn studie zien dat politieverhalen niet alleen over spannende gebeurtenissen gaan. Daarmee relativeert hij Waddingtons interpretatie van de politiekantinecultuur.

\section{Verhalen van plattelandspolitie}

Meestal hebben de door onderzoekers geanalyseerde politieverhalen vooral betrekking op het eigenlijke werk van politiemensen. Deze verhalen gaan met name over de vragen en problemen waarmee politiemensen in hun werk worden geconfronteerd, over de gevaren en risico's die zij daarbij tegenkomen, over het onderscheid tussen respectabele en niet-respectabele burgers (en hoe deze te herkennen), over voorbeelden van goed optreden, maar ook over onverwachte en soms hilarische situaties die politiemensen aantreffen.

De verhalen die hier centraal staan, hebben slechts deels betrekking op het eigenlijke werk. Zij gaan vooral over de specifieke identiteit die politiemensen op het platteland zichzelf toeschrijven als plattelandspolitie. Deze verhalen vertellen zij onderling, maar ook aan de onderzoeker als externe partij, om uit te leggen waarom de politie op het platteland 'heel anders' is dan de grootstedelijke politie. Deze verhalen maken duidelijk dat de plattelandsteams zich onderscheiden door eigen specifieke subculturele kenmerken. Hoewel deze verhalen misschien niet altijd letterlijk hoeven te worden genomen, bevatten zij belangrijke emotionele elementen: men heeft het gevoel dat de soort politie waar men voor staat en wil staan, onder druk staat en niet erkend wordt. Met hun verhalen brengen deze politiemensen het gevoel tot uiting dat zij door anderen in hun organisatie (waaronder mensen aan de top) worden beschouwd als slechts plattelandspolitie, een soort tweederangspolitie, die in kwaliteit minder zou zijn dan de grootstedelijke politie. ${ }^{3}$

Tegen dit beeld en oordeel verzet men zich in deze verhalen. Dat gebeurt niet door een uitgesproken rebellie, maar door een vaak terugkerende vertelvorm: men legt uit hoe politiewerk op het platteland 'werkt' en wat daarvan de kracht is. Tegelijk laat men zien dat de (stedelijke) bazen op afstand dit niet snappen en in hun arrogantie of onwetendheid hun eigen stedelijke denk- en werkwijze probe-

3 Young (1993) vond in Engeland een vergelijkbaar verschijnsel: daar sprak men van 'police in the sticks' (mogelijk te vertalen met 'boerenpolitie'). 
ren op te leggen. Dat kan vervolgens gemakkelijk fout gaan, maar gelukkig, zo wil een deel van de verhalen, weten politiemensen op het platteland de situatie nog te redden, dankzij hun voorsprong aan lokale kennis, op het platteland afgestemde vaardigheden en hun (overigens miskende) vakmanschap. Voorbeeld van een dergelijk verhaal is het volgende. Hierin zijn meerdere van deze onderdelen zichtbaar.

Op een gegeven moment komt via de meldkamer een melding dat in een dorp een man met een geweer op straat loopt. Het dorp lig ver weg van het politiebureau van het basisteam, minimaal 25 minuten rijden. Het is een klein, rustig en overwegend conservatief-christelijk dorp gelegen aan de rivierdijk, met een grotendeels agrarische bevolking. Na de melding is er bij de politie meteen groot alarm! Twee noodhulpmedewerkers zijn op dat moment niet ver van het dorp en rijden daarnaartoe. Voordat zij daar aankomen, krijgen zij opdracht van de dienstdoende OvDP op afstand te blijven, wat de twee noodhulpers ook doen. Deze OvDP is overigens werkzaam in de grote stad, buiten het gebied van het basisteam dat hij verder nauwelijks kent. Ondertussen is ook een seniormedewerker noodhulp op weg naar het dorp. Hij rijdt zijn surveillancedienst alleen. Ter plaatse aangekomen, treft hij zijn collega's aan die aan de rand van het dorp zich achter enkele struiken verschuilen en proberen te zien wat er in het dorp gaande is. De man met het geweer zou inmiddels ergens een boerderij zijn binnengegaan. Verder valt er niks bijzonders te zien. Het enige wat opvalt, is dat bij de betreffende boerderij dooie kraaien aan het hek hangen, maar dat is in dit soort dorpen niet uitzonderlijk. Terwijl zij met drie politiemensen staan te kijken, krijgen zij bericht dat zij niks mogen doen, want er komt een gewapende eenheid aan. Het kan echter nog ongeveer een halfuur duren voordat deze zal arriveren. Ondertussen ontstaat onrust in het dorp. Mensen vragen zich af wat er aan de hand is: twee politieauto's, drie politiemensen die half achter de bosjes staan te wachten en kijken. Er komen al mensen aan om nog eens beter te zien wat die politiemensen daar nu doen. Op een gegeven moment denkt de senior: 'Dit is toch geen manier van werken. Ik ga er op af!' Dus loopt hij op zijn eentje richting de boerderij, gaat daar achterom, klopt aan, roept: 'Volk!', waarna de boer er op zijn sokken aan komt en vraagt: 'Zo agent: wil je koffie?' Er blijkt helemaal niks aan de hand te zijn. De boer had last van kraaien, er zaten er weer een paar en hij had zijn geweer ('die daar in iedere boerderij aan een oude spijker hangt') gepakt en was erop af gegaan. Dat was alles. De gewapende eenheid kon weer teruggestuurd worden. Achteraf realiseerde de OvDP zich ook wel dat dit allemaal wat overdreven was.

'Ja', zei men, 'maar als bij ons in X (naam grote stad) een man met een geweer op straat loopt, dan treden wij altijd zo op. Ja, dat zal wel, maar hier is niet X. Hier gaan dingen anders en daar moet je politie op zijn afgestemd. Dat is nu juist het probleem en dat snapt men niet. Het liefst wil men daar politiemensen die er niet op af gaan, maar wachten op nadere bevelen en versterking van 20 man.' (Terpstra et al. 2016)

In dit voorbeeld zitten meerdere elementen die kenmerkend zijn voor de verhalen van politiemensen op het platteland. Deze verhalen gaan over veel meer dan de 
bekende klachten als lange aanrijtijden of het sluiten van bureaus. De kern van deze verhalen gaat om de soort politie die men denkt te zijn en wil zijn en over de relatie van de politie op het platteland met burgers.

De verhalen die plattelandspolitiemensen vertellen, kunnen worden uiteengerafeld in enkele componenten. Deze worden hierna langsgelopen.

Allereerst wordt in de verhalen sterk benadrukt dat binnen de politieteams op het platteland een andere wijze van omgang heerst tussen collega's dan bij de grootstedelijke politie gebruikelijk zou zijn: informeler en gemoedelijker. Op het platteland zou de politie ook op een andere wijze met burgers omgaan: informeler, minder de confrontatie zoekend en wat wel wordt omschreven als 'netter'. Dit wordt soms geillustreerd aan de hand van de wijze waarop jonge politiemensen in opleiding ('studenten') die al eerder een tijd bij een grotestadsteam hebben gezeten tegenover burgers optreden en hen bejegenen. In de grootstedelijke context hebben zij dat blijkbaar zo geleerd en wordt dat misschien geaccepteerd. In de context van het platteland wordt dat echter ervaren als 'onfatsoenlijk en kwetsend'. Deze wijze van optreden en het daarbij gehanteerde taalgebruik worden door politiemensen in het plattelandsteam vaak niet op prijs gesteld (en evenmin door veel burgers). In één verhaal gaat het over een situatie waarin de betreffende burger zich over het optreden van deze jonge politieman direct beklaagt bij de burgemeester.

Een belangrijk onderdeel van deze verhalen is dat de politie op het platteland andere opvattingen heeft over hoe politie in de praktijk werkt en hoort te werken: meer door middel van 'praten', problemen oplossend, met minder machtsvertoon, escalatie van middelen of gebruik van geweld. Het is minder een stijl van 'de straat blauw verven', een strategie die men kenmerkend acht voor de grootstedelijke politie. Omdat de stedelijke politie over de mensen en middelen beschikt om te escaleren, is dat volgens deze verhalen niet alleen uitgegroeid tot de kenmerkende manier van werken in de grote stad, maar ook tot het model waaraan daar 'goed' politiewerk wordt afgemeten.

Daartegenover wordt in de verhalen de wijze van optreden van de plattelandspolitie gezet. Op het platteland zouden politiemensen er sterker op uit zijn problemen 'al pratende' op te lossen. Bovendien zouden zij volgens dit verhaal beter in staat zijn op deze wijze op te treden dan de gemiddelde collega in de grote stad. Daarbij gaat het er volgens deze verhalen niet alleen om dat de problemen op het platteland mogelijk minder ernstig zijn, maar vooral dat politiemensen op het platteland over het noodzakelijke vakmanschap beschikken om problemen op deze wijze op te lossen. Op het platteland zijn politiemensen geen 'cowboys', zoals het in enkele gesprekken werd genoemd, een opvallend negatieve term die zij hanteren als het gaat om het optreden van sommige, maar in hun ogen blijkbaar typerende collega's in de stad. Politiemensen op het platteland zijn volgens deze verhalen bovendien veel meer dan hun grootstedelijke collega's generalisten die zich (willen) bezighouden met een breed scala van problemen en vragen. Daar valt ook veel kleine dienstverlening onder. Op het platteland kan de politie zich bezig- 
houden met een schaap dat in de sloot is beland. ${ }^{4}$ Weliswaar kunnen politiemensen op het platteland daar wat lacherig over doen, zij doen het wel en 'weten' dat dit er daar gewoon bij hoort. De gedachte dat allerlei 'kleine' dienstverlenende werkzaamheden kunnen (of moeten) worden afgestoten omdat zij niet tot 'de kerntaken van de politie' zouden horen, is hier zeker niet geaccepteerd: ook een schaap in nood hoort er hier bij.

Zoals uit het voorgaande al bleek, spreekt uit deze verhalen beroepstrots. Tegelijk is hier sprake van enige ambivalentie. Uit de verhalen blijkt animositeit en ressentiment te bestaan ten opzichte van de grootstedelijke politie. Vaak heeft men de indruk dat bij de leiding, maar ook bij opleidingsinstituten, de politie uit de grote stad als 'beter' wordt beschouwd. In deze verhalen wordt dit beeld omgedraaid: niet de politie op het platteland loopt achter, maar de politie in de grote stad zou iets van 'ons' kunnen leren. Dit argument wordt in de verhalen ook gebruikt om aan te geven dat veel van de van bovenaf opgelegde modellen niet passen bij de eigen lokale context van het platteland. Men ziet deze dan ook eigenlijk als achteruitgang en als een ontwikkeling naar een slechtere vorm van politiewerk. Tegelijk heeft men het gevoel als 'ouderwets' te worden beschouwd als men zich tegen deze modernisering van boven verzet: men voelt dat men de geaccepteerde argumenten dan niet aan zijn zijde heeft.

Een voorbeeld hiervan is de wijze waarop in een plattelandsteam gereageerd wordt op het initiatief van de eenheidsleiding tot een preventieactie rond diefstal en heling van mobieltjes. In het kader van die actie moeten wijkagenten voorlichting gaan geven op middelbare scholen. Wijkagenten in dit team menen dat dit probleem helemaal niet speelt op de scholen in hun gebied. Contact met schoolleiding bevestigt dat overigens. In het verhaal dat wijkagenten hierover vertellen, wordt de nadruk gelegd op het verschil in perspectief tussen stedelijke en plattelandspolitie. De eenheidsleiding (blijkbaar gezien als voorbeeld van stedelijke politie) zou volgens dit verhaal denken dat de problemen in de stad ook de problemen van hun plattelandsgebied zijn. Als de wijkagenten niet aan deze actie willen meedoen, hebben zij het gevoel dat zij zich moeten verdedigen omdat zij niet met hun tijd zouden meegaan.

Deze verhalen bevatten ook een historische component. Enerzijds zou de voor het platteland typerende stijl van politiewerk al een lange traditie hebben. Daarbij wordt soms verwezen naar het verleden van de rijkspolitie, soms nog steeds een bron van enige trots. In veel plattelandsteams zijn er wel enkele oudere medewerkers die nog symbolen van de rijkspolitie in hun bezit hebben, soms zichtbaar hebben uitgestald, zoals een asbak, lamp of riemkoppel. Anderzijds bevat de historische component ook een visie op de modernisering van de politie. Deze wordt vaak (minstens deels) ervaren als achteruitgang: door schaalvergroting, het wegtrekken van de politie van het platteland, de vermindering van aantallen bureaus en politiemensen, het verlies van een lokaal sterk geïntegreerde positie en door formalisering van het werk zouden veel 'goede' elementen van het traditionele 
politiewerk op het platteland verloren zijn gegaan. Enige heimwee naar het verleden speelt hier zeker een rol.

Het lijkt niet toevallig dat deze verhalen nu in een onderzoek naar lokale politie zo nadrukkelijk naar voren kwamen. In eerdere onderzoeken werden elementen van deze verhalen door politiemensen op het platteland wel genoemd, maar bleef het bij min of meer losse opmerkingen. Nu met de vorming van de Nationale Politie en het ontstaan van de basisteams wordt deze verhalen nieuw leven ingeblazen om het gevoel te verwoorden dat de plattelandsteams opgeslokt worden door de stedelijke politie, dat sprake is van miskenning van de eigen identiteit en trots op de wijze waarop men traditioneel werkt (of werkte). Zij geven uitdrukking aan het gevoel dat men 'gedwongen' wordt 'slechter werk' af te leveren. In die zin lijkt deels sprake van een reinvention of tradition (Giddens 1994).

Het gevoel dat men als plattelandspolitie onder druk staat en dat men de eigen identiteit en manier van werken moet inleveren, hebben wij Rotterdammisering van de politie genoemd: het gevoel onder politiemensen op het platteland dat men opgeslokt wordt door de politie in de grote stad waarbij men gedwongen wordt als de grootstedelijke politie te gaan werken (hetgeen men als achteruitgang beschouwt). Wij hebben hiervoor de term Rotterdammisering gebruikt (Terpstra et al. 2016), omdat in twee van de onderzochte plattelandsteams de vrees bestaat te moeten gaan werken als de politie in Rotterdam. Het zou overigens ook om een andere grote stad kunnen gaan. Dit is niet uniek voor Nederland. In Schotland spreekt men na de vorming van de nationale politie daar van Strathclydification: het gevoel bij de politie elders in Schotland dat men opgeslokt is door de politie uit Glasgow en omgeving. Ook daar gaat dat gepaard met het idee dat men gedwongen wordt te werken op een manier die niet past bij de plattelandscontext en die een verarming van het werk inhoudt (Terpstra en Fyfe 2015).

Deze verhalen bevatten ook een verklaring waarom de politie op het platteland 'anders' optreedt (en 'beter' zou functioneren) dan in de grote stad. Daarbij spelen twee elementen een centrale rol. In de verhalen komt telkens terug dat op het platteland politiemensen er bij een incident vanwege de lange aanrijtijden in de regel alleen of met zijn tweeën voor staan. Dat betekent dat zij in eerste instantie problemen op eigen kracht en met behulp van hun eigen inventiviteit moeten zien op te lossen. Assistentie van elders kan daar lang op zich laten wachten. In zo'n situatie is het belangrijk escalatie van conflicten te vermijden. Immers, de betreffende politiemensen staan er alleen of hoogstens met zijn tweeën voor. Om die reden proberen politiemensen op het platteland, aldus dit verhaal, problemen primair met 'de mond op te lossen' (zie voor vergelijkbare bevindingen in de VS bij plattelandspolitie: Christensen en Crank 2001).

Daarnaast wordt in de verhalen nog een tweede factor genoemd: op het platteland is de kans groter dat de politieman of -vrouw de betreffende burger waarmee een conflict dreigt al kent of kan verwachten deze nog vaker tegen te komen. Om later niet meteen weer problemen te hebben, is er alle reden de zaak niet op de spits te drijven. Politiemensen op het platteland hebben zich deze conflictdempende werkwijze eigen gemaakt, beschouwen deze als vanzelfsprekend en geven 
daarmee blijk van 'goed' politiewerk. Dit patroon werd overigens ook door Banton in 1964 opgemerkt.

Hiertegenover wordt in de verhalen de werkwijze van de politie in de grote stad geplaatst. In de stad kan versterking er binnen enkele minuten zijn. Daar zou de politie eraan gewend zijn snel te escaleren en de straat 'blauw te verven'. Daar zou men dit een normale gang van zaken vinden. In feite echter, aldus dit verhaal, is dit een stijl van politieoptreden die getuigt van minder vakmanschap.

\section{Slot}

Zijn deze verhalen van politiemensen van het platteland meer dan slechts 'een verhaal'? Drie overwegingen lijken hierbij relevant. Ten eerste valt op dat deze verhalen telkens weer opduiken, niet slechts op één plaats en/of één moment. Bovendien worden ze soms onderschreven door politiemensen in plattelandsteams die eerder in de grote stad werkten. Ook in andere landen, zoals Engeland (Young 1993), Schotland (Terpstra en Fyfe 2015; Wooff 2016) en de Verenigde Staten (Christensen en Crank 2001) circuleren vergelijkbare verhalen van politiemensen op het platteland. Dit duidt erop dat er een krachtige voedingsbodem is voor deze verhalen en de daaraan verbonden sentimenten. Het lijkt niet toevallig dat deze vooral opduiken in periodes van schaalvergroting en centralisatie van de politie.

Ten tweede, de vraag naar het werkelijkheidskarakter van deze verhalen mist eigenlijk het centrale punt. Het is duidelijk, deze verhalen berusten deels op stereotypen en simplificaties. Het belang van deze verhalen ligt echter ergens anders, namelijk in de geconstrueerde identiteit van de politie op het platteland en in de emoties en symboliek die in de verhalen een rol spelen. Zij zijn van direct belang om weerstanden in de basisteams op het platteland te begrijpen. Zo is het sluiten van een politiebureau op het platteland vanuit dit perspectief niet slechts het verplaatsen van een werkplek, maar gaat daar voor politiemensen (en burgers) een symbolische (en negatieve) werking van uit (vgl. McLaughlin 2008; Smith en Somerville 2013; Millie 2012). Het tegenargument dat deze verhalen niet waar, irrationeel of niet van deze tijd zijn, gaat aan de kern voorbij.

Tot slot, al zijn dit maar verhalen, toch lijkt daar wel een sociale basis voor aan te wijzen. De verhalen van de hedendaagse politiemensen op het Nederlandse platteland sluiten op een opmerkelijke wijze aan bij de al enige decennia oude analyses van Banton (1964) en Cain (1973). Een grotere sociale cohesie, sociale dichtheid en een sterkere morele consensus (en die zijn op het Nederlandse platteland meer aanwezig dan in de grote steden ( Knol 2002)) dragen in hun analyse niet alleen bij aan een andere positie van de politie in de plattelandssamenleving dan in de grote stad, maar ook aan een andere manier van optreden (meer gericht op het bewaren van vrede in plaats van handhaven) en tot een andere organisatie van de politie (minder gebaseerd op specialisatie). In de stedelijke samenleving staat de politie sociaal en cultureel meer op afstand. Dat betekent dat zij minder goed geïnformeerd is, minder alleen met 'praten' toe kan en daarom naar hardere middelen grijpt, aldus Cain. Op deze manier begrepen, zijn de verhalen van poli- 
tiemensen op het platteland veel meer dan alleen maar een 'verhaal'. Zij maken niet alleen duidelijk waarom juist in de plattelandsteams weerstand bestaat tegen schaalvergroting en centralisatie (onder meer in het kader van de vorming van de Nationale Politie), maar ook waarom schaalvergroting en verstedelijking tot een andere politie leiden. In die zin bieden de verhalen van plattelandspolitie een reflectie op de vraag waaraan een 'goede' politie moet voldoen, een vraag die verder reikt dan de plattelandscontext.

\section{Literatuur}

Banton, M. (1964) The Policeman in the Community. London: Tavistock.

Cain, M.E. (1973) Society and the Policeman's role. London/Boston: Routledge \& Kegan Paul. Chan, J.B.L. (1997) Changing Police Culture. Policing in a multicultural society. Cambridge: Cambridge University Press.

Christensen, W. en J.P. Crank (2001) Police work and culture in a nonurban setting: an ethnographic analysis. Police Quarterly, 4(1), 69-98.

Cockcroft, T. (2013) Police Culture. Themes and concepts. London: Routledge.

Duin, M.J. van et al. (2010) Politie en Bestuur in de Bible Belt: een verkenning. Apeldoorn: $\mathrm{P} \& W$.

Giddens, A. (1994) Living in a Post-Traditional Society. In U. Beck, A. Giddens en S. Lash (Eds.), Reflexive Modernization. Politics, Tradition and Aesthetics in the Modern Social Order. Cambridge: Polity, 56-109.

Gunther Moor, L. en J. Peeters (1996) Politie en Sociale Zelfredzaamheid van Burgers. Een onderzoek naar aanleiding van de vestiging en opheffing van politiebureaus. Dordrecht: SMP.

Hulst, M. van (2013a) Storytelling at the Police Station. The canteen culture revisited. British Journal of Criminology, 53(4), 624-642.

Hulst, M.J. van (2013b) Politieverhalen. Een etnografie van een belangrijk aspect van politieculturen. Apeldoorn: P\&W.

Knol, F. (2002) Stand van zaken en ontwikkeling van de fysieke kwaliteit van de woonomgeving. In J. de Hart (red.), Zekere banden. Sociale cohesie, leefbaarheid en veiligheid. Den Haag: SCP.

Loftus, B. (2009) Police Culture in a Changing World. Oxford: OUP.

Marshall, B. en S. Johnson (2005) Crime in Rural Areas: a review of the literature for the Rural Evidence Research Centre. London: Jill Dando Institute.

Mawby, R.I. (2004) Myth and Reality in Rural Policing. Perceptions of the police in a rural county of England. Policing. An International Journal of Police Strategies and Management, 27(3), 431-446.

Mawby, R.I. (2011) Rural Police: a comparative overview. In R.I. Mawby \& R. Yarwood (Eds.), Rural Policing and Policing the Rural. A Constable Countryside?. Farnham: Ashgate, 11-21.

Mawby, R.I. en R. Yarwood (Eds.) (2011) Rural Policing and Policing the Rural. A Constable Countryside?. Farnham: Ashgate.

McLaughlin, E. (2008) 'Last one out, turn off the "blue lamp"'; the geographical 'placing' of police performance management. Policing. A Journal of Policy and Practice. 2(3), 266-275.

Millie, A. (2012) Police stations, architecture and public reassurance. British Journal of Criminology, 52(6), 1092-1112. 
Shapland, J. en J. Vagg (1987) Using the Police. British Journal of Criminology, 27(1), 54-63. Shearing, C. en R. Ericson (1991). Culture as figurative action. British Journal of Sociology, 42(4), 481-506.

Smith, R. en P. Somerville (2013) The Long Goodbye: a note on the closure of rural policestations and the decline of rural policing in Britain. Policing. A Journal of Policy and Practice, 7(4), 348-358.

Terpstra, J. (2002) Sturing van Politie en Politiewerk. Een verkennend onderzoek tegen de achtergrond van een veranderende sturingscontext en sturingsstijl. Apeldoorn: $\mathrm{P} \& W$.

Terpstra, J. (2008) Wijkagenten en hun Dagelijks Werk. Een onderzoek naar de uitvoering van gebiedsgebonden politiewerk. Apeldoorn: P\&W.

Terpstra, J. (2009) Politiecultuur en Politiepraktijken: empirische en theoretische kanttekeningen bij een kernbegrip. In G. Meershoek (red.), Politiestudies: terugblik en vooruitzicht. Een bundel essays voor Kees van der Vijver. Dordrecht: SMVP, 133-152.

Terpstra, J. en N.R. Fyfe (2015) Mind the Implementation Gap? Police reform and local policing in the Netherlands and Scotland. Criminology and Criminal Justice, 15(5), 527-544.

Terpstra, J. et al. (2016) Basisteams in de Nationale Politie. Organisatie, taakuitvoering en gebiedsgebonden werk. Apeldoorn: P \& W.

Trujillo, N. en G. Dionisopoulos (1987) Cop Talk, Police Stories, and the Social Construction of Organizational Drama. Central States Speech Journal, 38(3/4), 196-209.

Van Maanen, J. (1978) The Asshole. In P.K. Manning en J. van Maanen (Eds.), Policing: A view from the street. Santa Monica: Goodyear.

Verwee, I. (2009) Wat Doet de Politie? Onderzoek naar de dagelijkse politiepraktijk. Cahiers Politiestudies, 2009-4, nr. 13, 37-66.

Waddington, P.A.J. (1999) Police (Canteen) Culture. British Journal of Criminology, 39(2), 287-309.

Weisheit, R.A. en L.E. Wells (1996) Rural Crime and Justice: implications for theory and research. Crime and Delinquency, 42(3), 379-397.

Weisheit, R.A., L.E. Wells en D.N. Falcone (1994) Community Policing in Small Town and Rural America. Crime and Delinquency, 40(4), 549-567.

Wooff, A. (2016) 'Soft' policing in rural Scotland. Policing. A Journal of Policy and Practice, published on line: 10.1093/police/paw031.

Yarwood, R. (2001) Crime and Policing in the British countryside: some agendas for contemporary geographical research. Sociologica Ruralis, 41(2), 201-219.

Yarwood, R. (2005a) Crime Concern and Policing in the Countryside. Evidence from Parish councilors in West Mercia Constabulary, England. Policing and Society, 15(1), 63-82.

Yarwood, R. (2005b) Beyond the Rural Idyll: Images, countryside changes and geography. Geography, 90(1), 19-31.

Young, M. (1993) In the Stings. Cultural identity in a rural police force. Oxford: OUP. 